\title{
OS VELHOS CAPOEIRAS ENSINAM PEGANDO NA MÃO
}

\author{
Pedro Rodolpho Jungers AbiB ${ }^{*}$
}

RESUMO: Esse artigo trata de analisar as formas tradicionais de transmissão dos saberes presentes no âmbito da cultura popular. A partir dessa abordagem, trazemos as experiências educacionais existentes no universo da capoeira angola - uma importante manifestação da cultura afro-brasileira - para uma reflexão sobre o papel dos mestres nesse processo. A memória, a ancestralidade, a ritualidade e a temporalidade são categorias fundamentais para compreendermos as relações de educação presentes nesse universo.

Palavras-chave: Memória. Capoeira. Educação não-formal. Mestre.

\section{THE OLD CAPOEIRA TEACH HOLDING HANDS}

ABSTRACT: This paper strives to analyze the traditional forms to transmit the knowledge present in popular cultures. The educational experience present in the Angola capoeira universe - an important manifestation of the Afro-Brazilian culture - is the ground for its reflection about the masters' function in this process. Memory, ancestrally, rituality and temporality are fundamental categories to understand the education relationships present in this universe.

Key words: Memory. Capoeira. Informal education. Master.

* Doutor em educação pela Universidade Estadual de Campinas (UNICAMP), professor adjunto da Faculdade de Educação da Universidade Federal da Bahia (UFBA) e capoeirista-discípulo do mestre João Pequeno de Pastinha. E-mail: pedrabib@ufba.br 
Pedro Rodolpho Jungers Abib

\section{$\dot{E}$}

Introdução

objetivo desse texto analisar os processos educativos não-formais presentes na capoeira angola, no sentido de levantarmos alguns aspectos importantes desses processos. Estamos buscando, assim, inspiração nas formas tradicionais de ensinar-aprender utilizadas nesse universo, sobretudo a partir das influências marcantes da cultura afrobrasileira, que caracterizam decisivamente as manifestações da cultura popular, para refletirmos sobre os modelos de aprendizagem, baseados na transmissão oral da memória coletiva de um grupo social, função exercida pelos mais velhos que são os responsáveis por disponibilizar os saberes e as tradiçōes daquele grupo social aos mais jovens. Através do reconhecimento sobre sua sabedoria e sua função social de guardiōes das tradiçôes, a comunidade atribui a eles o título de mestres.

Pretendemos, com isso, contribuir para uma reflexão mais aprofundada sobre as formas de educação presentes no universo da cultura popular, nas quais o mestre exerce papel fundamental, e de como essas experiências baseadas na tradição, na ancestralidade, no ritual, na memória coletiva, na solidariedade e num profundo respeito à sabedoria do mais velho, como principal responsável pela transmissão desses saberes às novas geraçōes, podem auxiliar num processo de construção de formas alternativas de se pensar a educação, sobretudo aquela voltada às camadas menos favorecidas da nossa sociedade. Estas são, em última instância, elas próprias as responsáveis por essas experiências ricas em conhecimentos e saberes que, normalmente, não são reconhecidos nem valorizados nos processos envolvendo a educação formal no Brasil.

Esse artigo é parte da pesquisa que originou a tese de doutorado em Ciências Sociais Aplicadas à Educação, defendida na Universidade Estadual de Campinas (unicamp), no ano de 2004, e valeu-se, além de pesquisa bibliográfica, também da metodologia da história oral, por meio de depoimentos colhidos junto a alguns dos mais importantes mestres de capoeira angola da Bahia.

Da roda de capoeira ao aprendizado da vida

Então eu ficava só olhando.

Aí ele disse assim:

Cad. Cedes, Campinas, vol. 26, n. 68, p. 86-98, jan./abr. 2006

Disponível em <http://www.cedes.unicamp.br> 
Os velhos capoeiras ensinam pegando na mão

- "Ô meu filho venha cá! Você quer aprender?"

Eu disse:

- Quero.

Ele mandou abaixar.

Quando eu abaixei, aí eu vi o pé...

Eu pulei.

Aí ele disse:

- "Ô meu filho, a partir de hoje eu vou lhe ensinar!"

Esse depoimento de Washington Bruno da Silva Filho, o mestre Canjiquinha, retrata a forma como tradicionalmente se ensinava e se aprendia capoeira. $\mathrm{O}$ mais velho sempre estimulando, a partir de uma situação real, o interesse do mais novo. O mais velho, nesse caso, era o famoso capoeira conhecido por Aberrê, o primeiro mestre de Canjiquinha. Esse fato se deu em 1935, em Matatu Pequeno, no bairro de Brotas, cidade de São Salvador, no banheiro de Otaviano, onde havia uma quitanda em frente. Ali aconteciam as vadiagens de capoeira (Abreu, 2002).

Assim também foi despertado o interesse do mestre João Pequeno de Pastinha, segundo ele próprio relata em depoimento que nos concedeu, logo quando chegou a Salvador, vindo de Mata de São João, no interior da Bahia, onde já tinha tido algumas experiências com capoeira, mas de forma ainda incipiente:

Naquele tempo, não tinha capoeira em espaço... a capoeira era na rua... aí eu não tinha arte, não tinha nada, eu fui trabalhar de servente de pedreiro... lá na rua Carlos Gomes. Eu trabalhava mais um camarada, na masseira, e ele chamava... o camarada chamava Cândido... e ele gostava de tomar umas pingas (risos)... quando o serviço tava lento, ele ia na rua, tomava umas pinga e vinha, batia palma, cantava, sapateava e dava pulo de capoeira... aí numa daquela que ele deu pulo de capoeira... eu entrei pra dar uma cabeçada e recebi uma joelhada por aqui [mostra o queixo] (risos). Aí ele me abraçou e disse: "olha, não se incomode não... vou lhe botar numa roda de capoeira (risos)".

Naquele tempo, a capoeira se aprendia "de oitiva", ou seja, sem método ou pedagogia. A oitiva constitui-se como um claro exemplo de como se dá a transmissão através da oralidade na capoeira, baseada na experiência e na observação. A oitiva era um processo diversificado e 
culturalmente muito rico, segundo Abreu (1999). O processo, na maior parte das vezes, dava-se na própria roda, sem a interrupção do seu curso. O mestre geralmente pegava nas mãos do aluno para "dar uma volta" com ele, dar os primeiros passos.

Diferentemente de hoje em dia, quando é mais freqüente se iniciar o aprendizado através de séries repetitivas de golpes e movimentos. Antigamente o lance inicial poderia surgir de uma situação inesperada, própria do jogo: um balão boca-de-calça, por exemplo. A partir dele se desdobravam outras situações inerentes ao jogo, que o aprendiz vivenciava orientado pelos 'toques' e conselhos do mestre. (Abreu, 1999, p. 20)

A roda pode ser considerada, então, conforme Abreu, como um rito de passagem que se incorporava ao processo de aprendizagem, como seu momento mais rico, aberto às influências e inventividades, quando o aluno, através dos toques e dicas do mestre que acompanhava atento o seu desenvolvimento, dos conselhos de outros camaradas da roda ou por si próprio, ia descobrindo as articulações, truques e manhas do jogo. A partir de então, ele começava a moldar o seu jeito de jogar. E começava a aprender algo mais sobre a vida.

Às vezes, esse aprendizado se dava também individualmente, nos quintais e terreiros das casas, onde a proximidade entre o mestre e o aprendiz era um fator essencial. Muitas vezes, como lembra o mestre Moraes - coordenador do Grupo de Capoeira Angola Pelourinho, em Salvador - em seu depoimento, o aprendiz de capoeira era também aprendiz de ofício do seu mestre de capoeira, que podia ser um marceneiro, um sapateiro ou um artesão, profissōes comuns entre os mestres de capoeira de antigamente. Moravam no mesmo bairro e tinham, geralmente, a mesma situação econômica, pois eram oriundos da mesma classe social. A convivência entre mestre e aprendiz era então um fator que auxiliava muito o processo de aprendizagem da capoeira.

Essa forma de ensinar e aprender guarda muito daquilo que poderíamos chamar de "pedagogia do africano", segundo expressão muito utilizada no âmbito da capoeira angola, que até hoje notamos nos mestres mais tradicionais, como João Pequeno, João Grande ou Curió, por exemplo, todos eles herdeiros do legendário mestre Pastinha, a maior referência da capoeira angola da Bahia.

Guardamos vivas, ainda na memória, lembranças das primeiras aulas no Forte Santo Antonio, há cerca de uma década, em que aprendía-

Cad. Cedes, Campinas, vol. 26, n. 68, p. 86-98, jan./abr. 2006 
mos os primeiros movimentos da capoeira angola pelas mãos de João Pequeno. A sensação de acolhimento ao sentirmos o toque das mãos daquele ancião, então beirando os oitenta anos, que, com todo carinho e delicadeza, conduzia nossos movimentos de braços e pernas pelo caminho sinuoso da capoeira angola, era uma sensação que talvez jamais esqueçamos. Nesses dez anos de convivência com a capoeira angola do mestre João Pequeno, em sua academia localizada no Forte Santo Antonio, em Salvador, somos nós próprios testemunhas desse processo de aprendizagem em que o mestre, o ancião, é figura principal e digna de respeito e admiração por parte dos aprendizes.

Segundo o mestre Moraes, em seu depoimento, o toque, na "pedagogia do africano", é fundamental. "Ele toca o aluno para passar o sentimento... ele não toca unicamente para consertar o movimento... ele passa muito mais a vontade de ver o aluno aprendendo, do que ensinar o movimento correto". Essa forma tradicional de ensinar passa pela proximidade que deve existir entre o mestre e o aprendiz. Uma proximidade corporal em que o afeto, a atenção e a disponibilidade do mestre mostram-se integralmente.

O mestre Cobra Mansa, outro estudioso das tradiçōes africanas, afirma, em seu depoimento, que o mestre tradicional verbaliza muito menos do que toca o seu aluno, e demonstra com seus próprios movimentos o que ele pretende ensinar. Segundo Cobra Mansa:

O mais importante nessa tradição é o hálito, é o que você tá passando... a sua alma que você tá transmitindo [faz o gesto como se estivesse passando a alma através da boca]. Então você não está transmitindo simplesmente a sua palavra, mas o hálito... a alma... então, quando você recebe aquilo, você tá recebendo uma tradição de muitos e muitos antepassados, porque alguém já me passou isso... agora eu tô passando pra você, você vai internalizar, e depois vai poder passar a mesma coisa para o outro, então é muito mais do que você pegar o livro e ler... tem uma alma ali, tem um gesto, um olhar, tem uma forma (...) tudo isso fica marcado, porque é legal você ler um livro, mas a emoção de alguém estar te contando uma coisa, te passando alguma coisa, tem todo um gesto, um brilho nos olhos, que você sente uma alma sendo passada para você.

Podemos afirmar que é essa a essência da oralidade, como uma forma de transmissão dos saberes e da cultura de um povo. O universo mítico que envolve a capoeira através da ancestralidade possibilita, segundo Luís Vítor Castro Jr. (2003, p. 9), 
Pedro Rodolpho Jungers Abib

(...) um caminho de comunicação vibrante que envolve seus personagens num campo fértil de produção de saberes, e que explica os fenômenos existentes. Os saberes revelam uma força de criação e recriação ordinária do passado em constante comunhão com o presente. Através de uma dimensão estética de educação baseada na descoberta, acontece um sistema de comunicação motora, simbólica e oral.

\section{Mestres e poetas: o sentido de se transmitir algo importante}

$\mathrm{Na}$ cultura popular, em geral, há sempre uma figura fundamental, responsável pelos processos envolvendo a memória coletiva: a figura do mestre. Os mestres exercem um papel central na preservação e transmissão dos saberes que organizam a vida social no âmbito da cultura popular, caracterizando, assim, a oralidade como forma privilegiada dessa transmissão. Recorremos à tradição grega para melhor argumentarmos sobre a função do mestre na cultura popular.

$\mathrm{Na}$ tradição grega, buscamos em Platão a idéia de que memória e conhecimento estão intimamente ligados, pois para esse filósofo conhecer é reconhecer, é rememorar. O conhecimento, no entanto, exige a purificação da paciência. Alfredo Bosi (1987) descreve uma passagem de uma alegoria construída por Platão, na qual as lembranças remontam a épocas distantes, a um momento em que a alma pudera contemplar as verdades ideais e eternas:

Os deuses, cruéis em sua sabedoria, exigiam um sacrifício: as almas deveriam esperar um tanto para que esse desejo se interiorizasse e se espiritualizasse dentro delas, pois entre um e outro ocorreria o tempo necessário à memória. A água oferecida pelos deuses era tirada do rio Lethe, rio do esquecimento. Se as almas, arrastadas pela sede do desejo sem freio, bebessem a água do Lethe, sem a pausa do sacrifício, ao invés de aprender, cairiam na letargia, que é um estado de sonolência, de embrutecimento, de inconsciência. Voltariam aos seus instintos brutos e, saciadas e entorpecidas muito rapidamente, seriam incapazes de dar o salto que leva ao conhecimento através da memória. Mas aquelas almas que esperassem e não tragassem sôfregas a água do Lethe alcançariam o não-esquecimento, o des-ocultamento, a a-letheia, a alethéia. Quem sofreia o desejo que, saciado, leva ao entorpecimento, consegue chegar à verdade, que é lembrança pura, memória libertadora. (Bosi, 1987, p. 53)

O poder de presentificação e invocação da musa da memória (Mnemosyne) cabem, segundo Marcel Detienne (1989), à palavra can- 
tada do poeta. Para o grego, a poesia tem o sentido de produção (poiesis): é a ação de trazer à presença algo que se mostrava oculto. A palavra do poeta é assim a palavra que, ao ser pronunciada, desvela aquilo que se mantinha encoberto, oculto (lethé), trazendo à tona a verdade (alethéia), instaurando e mantendo uma compreensão de mundo, em que todo um universo de significados se articula. Por isso, o momento de pronunciamento da palavra mítica se converte num acontecimento mágico-religioso que deve ser presidido por uma divindade. A divindade da memória (Mnemosyne) é que deverá ganhar voz no canto do poeta. O poeta é intermediário, meio por onde se pronunciará - e neste pronunciamento será evocado uma re-memoração conjunta, numa comemoração - o feito dos deuses e dos homens. O canto do poeta deverá rememorar o passado no presente, de modo que o grego possa decidir-se sobre sua ação futura. Memória e poesia se encontram no jogo de criação do mundo. Jogo do tempo: do que é, do que foi e do que será, que ao se mostrar no canto do poeta, instaura uma época histórica.

A figura do poeta exercia na polis a função política de manter viva a memória, de ser o guardião da ancestralidade de um povo - já que a Grécia arcaica se caracterizava por ser uma cultura ágrafa - e de ser aquele que traz a verdade (alethéia), pois era o intermediário entre os homens e os deuses. Ao evocar a figura do poeta, no pensamento grego, estamos aqui buscando traçar um paralelo na cultura popular, trazendo a figura do mestre como uma figura muito importante que exerce a função de ser portador e guardiáo da memória e da tradição do seu povo, função análoga à exercida pelo poeta na Grécia antiga.

Essa figura é fundamental no seio de uma cultura na qual a transmissão do saber passa pela via da oralidade e, por isso, depende desses guardióes da memória coletiva para que esta seja preservada e oferecida às novas gerações. $\mathrm{O}$ mestre é aquele que é reconhecido por sua comunidade, como o detentor de um saber que encarna as lutas e sofrimentos, alegrias e celebraçôes, derrotas e vitórias, orgulho e heroísmo das gerações passadas, e tem a missão quase religiosa de disponibilizar esse saber àqueles que a ele recorrem. $\mathrm{O}$ mestre corporifica, assim, a ancestralidade e a história de seu povo e assume, por essa razão, a função do poeta que, através do seu canto, é capaz de restituir esse passado como força instauradora, que irrompe para dignificar o presente e conduzir a ação construtiva do futuro. 
Poetas e mestres, mestres e poetas, capazes de desvendar, rememorar, anunciar, revestidos pela dignidade daqueles que conhecem e dão a conhecer. Ou, nas palavras de Michel Foucault (1995, p. 64),

(...) o poeta é aquele que, por sob as diferenças nomeadas e cotidianamente previstas, reencontra os parentescos subterrâneos das coisas, suas similitudes dispersadas. Sob os signos estabelecidos e apesar deles, ouve um outro discurso, mais profundo, que lembra o tempo em que as palavras cintilavam na semelhança universal das coisas.

Para Raul Iturra (1990), o saber oral, ao ficar consignado a gestos, palavras e interpretação de instrumentos e natureza, é um saber não só personalizado, como emotivo: a autoridade da palavra provém do convencimento de quem faz. Sabe, porque consegue fazer. O mestre dispõe dessa autoridade perante sua comunidade porque, antes de qualquer coisa, sabe fazer.

O mestre tem profunda ligação com a própria palavra tradição, que vem do latim: traditio. $\mathrm{O}$ verbo é tradere e significa precipuamente entregar, designa o ato de passar algo para outra pessoa, ou de passar de uma geração a outra geração. $\mathrm{O}$ verbo tradere tem relação também com o conhecimento oral e escrito. Isso quer dizer que, através da tradição, algo é dito e o dito é entregue de geração a geração. A tradição, para Nietzsche (1983), é a afirmação de que a lei tem vigência desde tempos imemoriais, e pô-la em dúvida constitui impiedade contra os antepassados. O mestre é aquele que permite que os saberes transmitidos pelos antepassados vivam e sejam dignificados na memória coletiva.

A capoeira angola nos traz exemplos belíssimos de como os saberes são transmitidos pacientemente pelo mestre, a exemplo do mestre João Pequeno de Pastinha, que na sua forma de ensinar revela um profundo sentimento de amor para com seus alunos - ou discípulos -, traduzido pelo respeito ao "tempo de aprender" de cada um, pela forma como toca corporalmente seus alunos para ensinar os movimentos, herança de uma pedagogia africana, baseada na proximidade entre o mestre e o aprendiz, onde até o hálito de quem ensina deve ser transmitido para aquele que aprende, como um meio por onde a tradição é repassada.

As músicas e ladainhas presentes no universo da capoeira são também elementos importantíssimos no processo de transmissão dos saberes, pois é através delas que se cultuam os antepassados, seus feitos he- 
róicos, seus exemplos de conduta, fatos históricos e lugares importantes para o imaginário dos capoeiras, o passado de dor e sofrimento dos tempos da escravidão, as estratégias e astúcias presentes nesse universo, assim como também as mensagens.

O mestre de capoeira é também o mestre de muitas das manifestações de nossa cultura popular, também é aquele que sabe ocultar determinados conhecimentos considerados "essenciais" dentro da tradição por ele representada. São saberes ou conhecimentos que não podem ser disponibilizados a qualquer pessoa ou em qualquer momento, mas necessitam, para serem transmitidos, de uma certa preparação por parte da pessoa interessada, que inclui muitas vezes uma "iniciação" que faz parte da ritualidade característica daquele grupo.

"O mestre reserva segredos, mais (sic) não nega explicação", diz mestre Pastinha em seus manuscritos, conforme Ângelo Decânio (1996). Conhecido no meio da capoeira como "pulo do gato", esse conhecimento só é disponibilizado àqueles que demonstram amadurecimento e compromisso suficientes para poderem utilizá-lo em benefício da própria preservação da tradição. Essas estratégias são importantes no sentido de manter certa coesão em torno desses saberes e tradiçōes, fundamentais em relação ao sentimento de pertencimento identitário e de transmissão da memória coletiva do grupo, que se constitui a partir dessas práticas. Pastinha utilizava freqüentemente em seus escritos o termo "mestrar", referindo-se ao ato de ensinar e transmitir os conhecimentos referentes à tradição da capoeira angola.

Tradicionalmente, como diz Muniz Sodré (2002), o mestre não ensinava o seu discípulo, pelo menos no sentido que a pedagogia ocidental nos habituou a entender o verbo ensinar. Ou seja, o mestre não verbalizava, nem conceituava o seu conhecimento para transmiti-lo metodicamente ao aluno. "Ele criava as condiçōes de aprendizagem formando a roda de capoeira e assistindo a ela. Era um processo sem qualquer intelectualização, como no zen, em que se buscava um reflexo corporal, comandado não pelo cérebro, mas por alguma coisa resultante da sua integração com o corpo" (Sodré, 2002, p. 38).

Mestre Pastinha dizia, aos 92 anos de idade, pouco antes de morrer: "eu ainda tô aprendendo capoeira...". Essa paciência em deixar o tempo agir como escultor das qualidades de um bom capoeira ainda pode ser encontrada em alguns poucos grupos de capoeira angola, diferente- 
mente da maioria dos grupos de capoeira regional, onde, em boa parte, a própria função de mestre tem se banalizado, pois é cada vez mais freqüente encontrarmos jovens capoeiras, na faixa de seus vinte ou trinta anos, se auto-intitulando mestres, com pouca experiência de vida e de capoeira, sem a mínima noção do que essa titulação - o "ser mestre" significa.

Isso se dá em função de interesses em relação ao mercado consumidor de cultura que cresce a cada dia, no qual se inclui a capoeira e no qual o título de mestre é uma garantia de obtenção de espaços nesse concorrido "shopping cultural da modernidade". A capoeira angola também não está livre dessa influência, porém nota-se certa preocupação, talvez um pouco maior do que na capoeira regional, com esse tempo de chegar a ser mestre, embora já tenhamos muitos exemplos também no universo da capoeira angola que contradizem essa nossa análise.

Diz uma cantiga de capoeira que "só o tempo te faz mestre, não o diploma que comprou", e isso implica que o mestre de capoeira seja alguém que possua, além da capacidade e habilidade na prática do jogo, muita experiência de vida. $\mathrm{O}$ reconhecimento como mestre (tanto na capoeira, quanto na cultura popular em geral) se dá então naturalmente, por parte da comunidade da qual ele faz parte, por entender que foram preenchidos os atributos exigidos para tal função. O título de mestre só tem legitimidade quando atribuído pelo grupo social ao qual representa, que, em última instância, é quem delega autoridade às suas lideranças.

O soba na cultura bantu, segundo Antonio Miguel André (2003), é a denominação da função exercida pelo velho, aquele que detém a memória e o conhecimento sobre os costumes, a língua e a história de sua comunidade, exercendo a liderança desse grupo social e decidindo sobre questôes referentes à justiça entre seus pares. Ele só se reveste desse poder e dessa autoridade justamente por ser velho e, portanto, ter adquirido a experiência necessária para exercer tal função. A função de mestre na capoeira angola deve, ou deveria ser pautada por esses mesmos princípios, já que ser mestre resulta do aprendizado, experiência e observação de toda uma vida.

Assim, o mestre, na cultura popular em geral, adquire esse reconhecimento por ter se notabilizado perante sua comunidade, em razão de sua capacidade de ser um elo transmissor dos saberes de seus antepassados. Esse processo, na cultura bantu, reveste-se de importância ca- 
pital, pois essa cultura põe em estreita relação os antepassados e seus descendentes, convencidos estes de que não continuariam a existir no presente e não poderiam perpetuar sua linhagem sem a proteção dos antepassados. Devem, pois, segundo Kagame (1975), voltar-se para seus antepassados para se certificarem da intervenção tutelar que esperam deles, mas isso não significa de modo algum que eles não se orientam para os tempos que virão, pois o fim último do homem, em seu sistema filosófico, é a perpetuação da linhagem. Eles se voltam, pois, para o passado, a fim de garantirem seu futuro individual e o futuro de sua descendência.

O culto aos antepassados que se manifesta na capoeira angola, influência direta da concepção bantu de tempo - que não é linear, mas sim circular -, nota-se com muita ênfase através dos cantos e ladainhas em que os ancestrais da capoeira são sempre lembrados e mesmo através da forma como esses antepassados são reverenciados, seja nos discursos dos mestres e alunos, seja na presença de fotografias, imagens e pinturas desses antepassados presentes de forma solene nas paredes dos locais onde acontecem as aulas e rodas de capoeira angola; seja ainda na forma pela qual a maioria dos angoleiros faz questão de se referir à sua "linhagem" - a árvore genealógica da capoeira -, como prova de pertencimento à tradição herdada de determinado mestre considerado importante nesse universo.

A capoeira angola, ao buscar constantemente os vínculos com essa ancestralidade africana, e também com a ancestralidade que tem como referência os tempos de escravidão no Brasil e, posteriormente, os tempos remotos da capoeira de rua, das desordens e vadiagens, procura estabelecer o elo entre o seu passado ancestral, o seu presente constituído e o seu futuro enquanto possibilidade concreta de afirmação social, cultural e política. Manifesta-se, assim, principalmente a partir do ritual da roda, a noção de circularidade do tempo na capoeira angola, e os processos de aprendizagem presentes em seu universo acabam por serem também, em certa medida, influenciados por essa concepção de tempo.

\section{Considerações finais}

Buscamos, neste texto, uma aproximação com as formas tradicionais de transmissão dos saberes pertinentes a grupos sociais geralmente excluí- 
dos, considerados atrasados e rudimentares, assim como é vista a maior parte das manifestaçóes tradicionais populares por certos setores da intelectualidade acadêmica. Nossa percepção é outra. Pela beleza em que se constroem as relaçóes de pertencimento, o sentido de identidade, o respeito pela tradição e pelos antepassados, e pela simplicidade e alegria com que se celebra a vida, entendemos que a cultura popular nos tem muito a ensinar.

O campo das ciências sociais muito tem discutido atualmente sobre a necessidade de se validar os saberes oriundos da tradição popular, da experiência e do cotidiano. Os saberes, qualquer que seja sua origem - popular ou acadêmico-científica -, devem ser valorizados sem hierarquizaçôes, preconceitos ou discriminaçōes. É preciso uma racionalidade mais ampliada, que possibilite validar esses saberes que, segundo Boaventura Souza Santos (2002), foram "produzidos para não existirem, violentados e ocultados por uma racionalidade estreita, perversa, e profundamente preconceituosa".

Nesse sentido, entendemos ser fundamental o debate acerca da memória, da ancestralidade, da oralidade e da ritualidade, sobretudo quando se trata de grupos sociais que lutam para preservar sua cultura e suas tradiçôes, e do papel que exercem os processos educacionais nesses contextos, onde as formas de transmissão dos saberes podem nos permitir uma profunda reflexão sobre as possibilidades de pensar novos caminhos para a educação formal em nosso país.

O século XXI aponta para avanços importantes no sentido de aceitação de diferenças, de luta contra o preconceito e a discriminação, do direito à igualdade de oportunidades e de políticas públicas de inclusão social. O campo da educação formal, principalmente, precisa refletir de forma profunda sobre suas práticas, no sentido de poder acolher as ricas experiências educacionais provenientes da cultura popular, representadas pelas formas tradicionais de transmissão dos saberes de uma comunidade. Nesse sentido, a capoeira e os mestres têm muito a ensinar.

Recebido em setembro de 2005 e aprovado em março de 2006.

\section{Referências bibliográficas}

ABREU, F.J. Bimba é Bamba: a capoeira no ringue. Salvador: Instituto Jair Moura, 1999. 
Os velhos capoeiras ensinam pegando na mão

ABREU, F.J. O barracão do mestre Waldemar: Salvador: Zarabatana, 2003 .

ANDRÉ, A.M. A voz de um saber: o papel do velho entre os povos Kimbundu. In: GuSMÃO, N. (Org.). Infância e velhice: pesquisa de idéias. Campinas: Alínea, 2003.

BOSI, A. Cultura brasileira: tradição e contradição. Rio de Janeiro: Zahar; FUNARTE, 1987.

CASTRO JUNIOR., L.V. Capoeira angola: olhares e toques cruzados entre historicidade e ancestralidade. Revista Brasileira de Ciências do Esporte, Porto Alegre, v. 25, n. 1, 2003.

DECÂNIO FILHO, A. A herança de Pastinha. Salvador:, 1996. (São Salomão, 3)

DETIENNE, M. Os mestres da verdade da Grécia arcaica. Rio de Janeiro: Zahar, 1989.

FOUCAULT, M. As palavras e as coisas. São Paulo: Martins Fontes, 1995.

ITURRA, R. Fugirás à escola para trabalhar a terra. Lisboa: Escher, 1990.

KAGAME, A. A percepção empírica do tempo e concepção da história no pensamento Bantu. In: Ricouer, R. (Org.). As culturas e o tempo: estudos reunidos pela UNESCO. Rio de Janeiro: Vozes, 1975.

NIETZSCHE, F. $O$ anticristo: ensaio de uma crítica do cristianismo. São Paulo: Abril Cultural, 1983. (Coleção Os Pensadores).

SANTOS, B.S. Sociologia das ausências: sociologia das emergências. Conferência proferida durante o 11. Congresso Brasileiro de Sociologia, Universidade Estadual de Campinas (UNICAMP), 2003.

SODRÉ, M. Mestre Bimba: corpo de mandinga. Rio de Janeiro: Manati, 2002. 